\title{
GUEST EDITORIAL \\ Mental health impact of the war on drugs
}

\author{
M. Malliori, ${ }^{1}$ C. Golna, ${ }^{2}$ K. Souliotis ${ }^{3}$ and M. L. Kraus ${ }^{4}$
}

${ }^{1}$ Associate Professor of Psychiatry, Athens University Medical School, Greece, email mmalliori@ otenet.gr

${ }^{2}$ Scientific Director, Hepatitis B and C Public Policy Association Maroussi, Greece, email c.golna@ gmail.com

${ }^{3}$ Associate Professor of Health Policy, Faculty of Social and Political Sciences, University of Peloponnese, Corinth, Greece, email soulioti@hol.gr

Assistant Clinical Professor of Medicine, Yale University School of Medicine, New Haven, Connecticut, USA, emailmkl@ wsmgct.com
Further to the publication by the London School of Economics and Political Science of the report Ending the Drug Wars, this editorial focuses on the mental health impact of the 'war on drugs' and on the need to end such policies in favour of evidence-based interventions to manage drug dependence as a health condition.

Last year, the London School of Economics and Political Science (LSE) published a report, Ending the Drug Wars, which stated:

the pursuit of a militarised and enforcement-led global 'war on drugs' strategy has produced enormous negative outcomes and collateral damage, including mass incarceration in the US, highly repressive policies in Asia, vast corruption and political destabilisation in Afghanistan and West Africa, immense violence in Latin America, an HIV epidemic in Russia, an acute global shortage of pain medication and the propagation of systematic human rights abuses around the world. (LSE Expert Group on the Economics of Drug Policy, 2014: p. 3)

The report claims that "it is time to end the "war on drugs" and massively redirect resources towards effective evidence-based policies underpinned by rigorous economic analysis' (p. 3). Throughout the report it is clear that the public health, safety and economic burden of the war on drugs has been grave and not cost-effective in terms of return on investment. Its toll on health has been particularly evident in the area of mental health, especially for prisoners incarcerated for drug-related crimes and after their release into the community.

In 2011, nearly half (48\%) of inmates in US federal prisons were serving time for drug offences (Carson \& Sabol, 2012). Latin America is equally immersed in a drug-related prison epidemic. Harsher criminal penalties underlie the increase in the prison population. The number of women incarcerated in the region nearly doubled between 2006 and 2011, from 40000 to 74000, and drug crimes were the first or second most frequent reason for their incarceration (Giacomello, 2014). Of a total of 9 million prisoners in the world, approximately $40 \%$ are held on charges related to drugs.

Within prisons, mental health challenges are distinctly more prevalent and result in a substantial health burden for inmates and society. Compared with the general population, prison inmates experience poorer physical and mental health and social well-being, including both acute and long-standing physical and mental illness and disability, sexual health problems, suicide, self-harm, physical, psychological and sexual violence, lower life expectancy and breakdowns in family and other relationships, as well as drug, alcohol and tobacco dependency (Barry et al, 2010). In the USA, more than half of the approximately 2.2 million prison and jail inmates at the end of 2010 experienced a mental health problem (Glaze, 2011): $44-64 \%$ had mental health issues and $74-76 \%$ had substance misuse issues (James \& Glaze, 2006). In Europe, a systematic review of 62 surveys of about 23000 prisoners from 12 countries confirmed that up to $65 \%$ of prisoners have a mental health disorder, which may range from personality disorder (42-65\%), to major depression (10-12\%) to psychotic illnesses $(4 \%$, including schizophrenia, manic episodes and delusional disorder). Prisoners are several times more likely to have psychosis and major depression and about ten times more likely to have antisocial personality disorder than the general population (Fazel \& Danesh, 2002). Those disorders represent a serious risk factor for suicide, which is the leading cause of death among those who are imprisoned and accounts for around onethird of all prison deaths. In Europe, the risk of suicide among prisoners ( 10.5 per 10000 in prison) is estimated to be seven times that of the general population (Rabe, 2012); in the USA, suicide was the most frequent reason for the 4150 deaths among inmates in 2010 (Noonan, 2012).

Time in prison is plagued by violence. Both men and women with mental disorders are disproportionately represented among victims of physical violence inside prison. Rates of physical victimisation for men with any mental disorder were higher than those of men with no mental disorder, by a factor of 1.6 for inmate-on-inmate incidents and a factor of 1.2 for staff-on-inmate victimisation. Female inmates with mental disorder were 1.7 times more likely to report being physically victimised by another inmate than did their counterparts with no mental disorder (Blitz et al, 2008).

This situation is exacerbated for inmates who use drugs. Data from the USA, Canada and Australia show that the prevalence of drug use among prisoners prior to incarceration is substantially above the level in the general population. In studies carried out in Europe since 2000, estimates of the prevalence of injecting illicit drugs while in prison range from $2 \%$ to $31 \%$ (EMCDDA, 2012). This is particularly critical for users who switch drugs inside prisons due to lack of availability of their drug of choice. Additionally, the high prevalence of HIV and hepatitis C infection among prisoners and pre-trial detainees, combined with 
overcrowding and substandard living conditions, sometimes amounting to inhuman or degrading treatment in violation of international law, make prisons and other detention centres a high-risk environment for transmission. Ultimately, this contributes to epidemics in the communities to which prisoners return upon their release (Jurgens et al, 2011).

After release, prisoners do not have an easier time. Release from prison has been associated with increased health burden, including mortality from all causes and, in particular, from drug overdose. A review of drug-related deaths that occurred shortly after release from prison in Europe, Australia and the USA showed that six out of ten deaths in the first 12 weeks after release were drug-related (Merrall et al, 2010). This risk does not appear to have decreased in the last 20 years (World Health Organization Regional Office for Europe, 2010). It is experienced by an increasing population of drug users whom the 'war on drugs' has sent to prison rather than to appropriate care and treatment.

The principles underpinning that 'war' (militarisation, control, imprisonment) continue to undermine the impact of repeated calls to shift the emphasis from law enforcement, punishment and interdiction towards public health, prevention, harm reduction and treatment-oriented policies. This shift could save lives, ease the burden of mental ill-health and communicable diseases on healthcare systems and deliver sustainable savings in healthcare and social welfare (Room \& Reuter, 2012). The 'war on drugs' principles feed the fear of relinquishing strict control over people who use drugs, resulting in their incarceration, which maintains them in the same vicious cycle, rather than assisting them to access continuing care and treatment for their dependence.

In spite of a substantial body of evidence demonstrating the benefits of evidence-based, drug-related health services in the prison setting and the community, such services remain underfunded, unavailable or inadequate to meet an increasing need. Thus, a major opportunity to improve public health within prisons and beyond, save on critical resources and maximise public good (Strang et al, 2012) is sacrificed on the altar of misconceptions and moral pseudo-dilemmas.

There is now, though, renewed interest in sweeping reform to end the persistent criminalisation of drug users - including developing programmes of general amnesty for the prisoners of drug wars. The Europe Union's Drugs Strategy 2013-20 (European Council, 2012) calls on member states to increase the use of effective alternatives to the incarceration of drug-using offenders. At a time when treatment for people using drugs is of immense value in terms of personal and public health, social welfare and economics, it is critical to recognise that drug policy, like any policy, must be defined, applied and evaluated against measurable goals and results, and not determined by fear, ideology, intentions or short-term politics.

\section{References}

Barry, J. M., Darker, C. D., Thomas, D. E., et al (2010) Primary medical care in Irish prisons. BMC Health Service, 10(74), 1-6.

Blitz, C., Wolff, N. \& Shi, J. (2008) Physical victimization in prison: the role of mental illness. International Journal of Law and Psychiatry, 31, 385-393.

Carson, E. \& Sabol, W. (2012) Prisoners in 2011. US Department of Justice. Available at http://www.bjs.gov/content/pub/pdf/p11.pdf (accessed June 2015).

EMCDDA (2012) Prisons and Drugs in Europe: The Problem and Responses. European Monitoring Centre for Drugs and Drug Addiction. Available at http://www.emcdda.europa.eu/publications/ selected-issues/prison (accessed June 2015).

European Council (2012) EU Drugs Strategy 2013-20 (2012/C 402/01). EU. Available at http://eur-lex.europa.eu/LexUriServ/ LexUriServ.do?uri=0]:C:2012:402:0001:0010:en:PDF (accessed June 2015).

Fazel, S. \& Danesh, J. (2002) Serious mental disorder in 23000 prisoners: a systematic review of 62 surveys. Lancet, 359, 545-550.

Giacomello, C. (2014) Proposals for Alternatives to Criminal Prosecution and Incarceration for Drug-Related Offenses in Latin America (IDPC Briefing Paper). International Drug Policy Consortium. Available at https://dl.dropboxusercontent. com/u/64663568/library/IDPC-briefing-paper_Alternatives-toincarceration-in-LA ENGLISH.pdf (accessed June 2015).

Glaze, E. (2011) Correctional Populations in the United States, 2010. US Department of Justice. Available at http://www.bjs.gov/ content/pub/pdf/cpus10.pdf (accessed June 2015).

James, D. \& Glaze, L. (2006) Mental Health Problems of Prison and Jail Inmates (Bureau of Justice Statistics, Special Report). US Department of Justice. Available at http://www.bjs.gov/content/ pub/pdf/mhppji.pdf (accessed June 2015).

Jurgens, R., Nowak, M. \& Day, M. (2011) HIV and incarceration: prisons and detention. Journal of the International AIDS Society, 14,26 .

LSE Expert Group on the Economics of Drug Policy (2014) Ending the Drug Wars. LSE. Available at http://www.lse.ac.uk/IDEAS/ publications/reports/pdf/LSE-IDEAS-DRUGS-REPORT-FINAL-WEB01. pdf (accessed June 2015)

Merrall, E., Kariminia, A., Binswanger, I. A., et al (2010) Metaanalysis of drug-related deaths soon after release from prison. Addiction, 105, 1545-1554.

Noonan, M. (2012) Mortality in Local Jails and State Prisons 2000-2010 - Statistical Tables. US Department of Justice. Available at http://www.bjs.gov/content/pub/pdf/mljsp0010st.pdf (accessed June 2015).

Rabe, K. (2012) Prison structure, inmate mortality and suicide risk in Europe. International Journal of Law and Psychiatry, 35, 220-230.

Room, R. \& Reuter, P. (2012) How well do international drug conventions protect public health? Lancet, 379, 84-91.

Strang, J., Babor, T., Caulkins, J., et al (2012) Drug policy and the public good: evidence for effective interventions. Lancet, 379 $71-83$

World Health Organization Regional Office for Europe (2010) Prevention of Acute Drug-Related Mortality in Prison Populations During the Immediate Post-release Period. WHO.

\section{BJPsych International on Facebook} https://www.facebook.com/ B]PsychInternational 